\title{
SISTEM INFORMASI SIMPAN PINJAM KOPERASI PEGAWAI PADA SMK YUPPENTEK 1 TANGERANG
}

\author{
Abdul Hayat ${ }^{1}$ \\ Euis Sitinur Aisyah ${ }^{2}$ \\ Serly Ovtavia Ningrum ${ }^{3}$ \\ e-mail : abdul.hayat@raharja.info, euis@ @raharja.info, serly@ raharja.info,
}

\begin{abstract}
Management of credit unions in SMK Yuppentek 1 Tangerang, still using the book and Microsoft Excel. This method is less effective for transactions occurring savings and loans so that the higher the count is also growing.besides activities of saving and borrowing data backup process is not automatically and inadequate storage placeso that the accumulation of papers. Given these problems, it needs to use cooperative savings and loan applications that can assist in the process of data processing and accounting of savings and loans. The research method used in this research literature, interviews, observation, analysis system, design system, and implementation system. The expected outcome of this research is with using database MySql.
\end{abstract}

Keywords: credit union, $M y S q l$

\begin{abstract}
ABSTRAK
Pengelolaan koperasi simpan pinjam di SMK Yuppentek 1 Tangerang ini masih menggunakan sistem konvensional yaitu menggunakan buku dan Microsoft Excel. Cara ini masih kurang efektif karena transaksi simpan pinjam yang terjadi semakin tinggi sehingga perhitungan juga semakin marak, selain kegiatan simpan pinjamnya proses backup data tidak secara otomatis dan kurang memadainya tempat untuk menyimpan datadata, sehingga terjadinya penumpukan kertas-kertas. Dengan adanya permasalahan tersebut, koperasi ini perlu menggunakan aplikasi simpan pinjam yang dapat membantu dalam proses pengolahan data simpan pinjam dan akuntasi. Adapun metode penelitian yang digunakan dalam penelitian ini yaitu pustaka, wawancara, observasi, analisis sistem,perancangan sistem, dan implementasi sistem. Hasil yang diterapkan dalam penelitian ini adalah dengan menggunakan database MySql.
\end{abstract}

Kata Kunci: Koperasi Simpan Pinjam, database MySql

\section{PENDAHULUAN}

Koperasi merupakan suatu badanyang didirikan atas azas kekeluargaan dimana tujuan utamanya adalah untuk mensejahterakan para anggotanya. Koperasi berupaya terus untuk terus meningkatkan permodalan baik melalui rupa-rupa simpanan, penyerapan dan titipan pihak ketiga maupun penarikan kembali piutang jangka panjang serta usaha-usaha lain. Semua itu dilakukan agar koperasi dapat mengimbangi tuntutan anggota dalam hal pendanaan dana segar dalam jumlah besar, sehingga para anggota tidak terlibat dngan para renternir serta bank yang biasanya bersuku bunga tinggi, di jaman kita yang modern ini sudah banyak sekali sistem komputer yang sangat membantu kita dalam kehidupan sehari-hari namun di SMK 
Yuppentek 1 ini masih menggunakan sistem semi manual yaitu melakukan pencatatanpencatatan arsip data terlebih dahulu dan setelah itu dimasukan ke dalam komputer yaitu Microsoft Office, Word, Excel, sehingga banyak penumpukan surat permohonan peminjaman dan laporan yang dibuae memerlukan waktu lama dengan demikian hasil yang diperoleh maaih kurang memuaskan. Penggunaan komputer dalam dalam mengelolaan data simpan pinjam merupakan langkah yang sangat efektif karena dilihat dari cara kerjanya serta dalam keefesienan waktu itu lebih optimal serta memuaskan.

Dengan adanya permasalahan tersebut, SMK Yuppentek 1 perlu menggunakan sistem terkomputerisasi untk mempermudah dalam pengaplikasian data.

\section{PERMASALAHAN}

Berdasarkan uraian diatas dan pengamatan yang dilakukan, maka dapat diuraikan beberapa permasalahan yang dihadapi, antara lain:

1. Bagaimana sistem informasi simpan pinjam koperasi pada SMK Yuppentek 1 Tangerang?

2. Permasalahan apa saja yang ada pada sistem informasi simpan pinjam koperasi yang sedang berjalan pada SMK Yuppentek 1 Tangerang ?

3. Bagaimana rancangan sistem simpan pinjam yang diusulkan pada pegawai SMK Yuppentek 1 Tangerang?

\section{TUJUAN DAN MANFAAT}

Membangun Sistem Informasi dalam pengolahan data simpan pinjam merupakan langkah yang tepat dalam mencapai hasil yang maksimal. Jika dilihat dari cara kerjanya, untuk keefisienan waktu, kecepatan dalam waktu pemprosesan serta keefektifan kerja menggunakan komputer akan memberikan hasil yang optimal serta memuaskan dibandingkan dengan menggunakan cara yang manual. Sementara itu, manfaat pembangunan sistem informasi simpan pinjam koperasi pegawai pada SMK Yuppentek 1 Tangerang ini memberikan manfaat untuk:

a. Mempermudah petugas koperasi menyimpan data simpan pinjam dan mempercepat pembuatan laporan bulanan pada Koperasi Pegawai SMK Yuppentek 1 Tangerang.

b. Sistem dapat mengimbangi tuntutan anggota dalam hal pengadaan dana segar dalam jumlah besar, sehingga dengan demikian anggota koperasi tidak harus terjebak pada praktek-praktek rentenir maupun pinjam uang ke bank yang biasanya bersuku bunga tinggi.

\section{HASIL DAN PEMBAHASAN}

\section{Rancangan Sistem yang diusulkan}

Berikut ini diagram dan analisa sistem yang diusulkan, penulis menggunakan Visual Paradigm for UML Versi 6.4 Enterprise Edition pada penelitian. 


\section{Usecase Diagram Simpan Pinjam}

\section{Koperasi Yang di Usulkan}

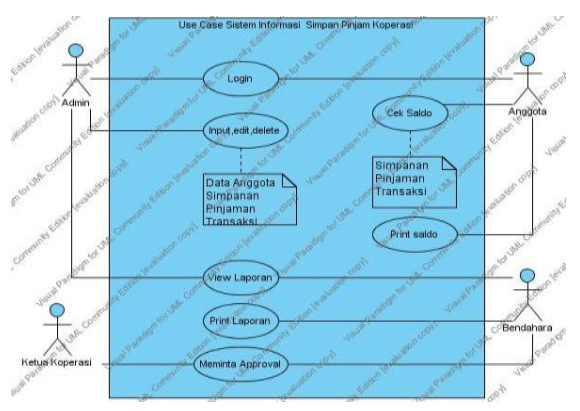

\section{Gambar 1. Usecase Diagram Simpan}

Pinjam Koperasi

Berdasarkan gambar 1 Use Case Diagram berikut ini adalah penjelasan skenario sistem yang diusulkan:

1. Sebuah sistem yang mencakup seluruh kegiatan pada simpan pinjam koperasi pegawai pada SMK Yuppentek 1 Tangerang.

2. Terdapat 4 actor yang melakukan kegiatan, yaitu Admin, ketua koperasi, anggota, dan bendahara.

3. Terdapat 7 use case yang bisa dilakukan oleh actor-actor tersebut diantaranya input, edit, delete yaitu Admin dapat melakukan input, edit dan delete data anggota, simpanan, pinjaman dan transaksi. Use case View yaitu laporan admin dan bendahara dapat melihat laporan tahunan mengenai simpanan, pinjaman dan transaksi. Use case print laporan yaitu admin atau bendahara dapat melakukan print out laporan tahunan simpanan, pinjaman dan transaksi. Use case minta approval yaitu admin dapat meminta approval kepada ketua koperasi. Use case cek saldo yaitu anggota koperasi dapat mengecek saldo simpanan, pinjaman dan transaksi. Dan use case print saldo yaitu anggota dapat melakukan print out saldo yang ditampilan.

\section{Rancangan Basis Data}

Rancangan basis data digunakan sebagai media penyimpanan data yang dipergunakan dalam aplikasi dan database membantu pemrograman dalam menampilkan data. Hasil analisa pada sistem yang dihasilkan terdapat beberapa rancangan yang diusulkan. Dari rancangan tersebut akan dibentuk rancangan basis data untuk mempermudah melihat bentuk file dan isinya. Berikut ini adalah penjelasan tentang proses perancangan basis data memakai class diagram, spesifikasi basis data dan normalisasi.

\section{Class Diagram Simpan Pinjam Koperasi Yang Diusulkan}

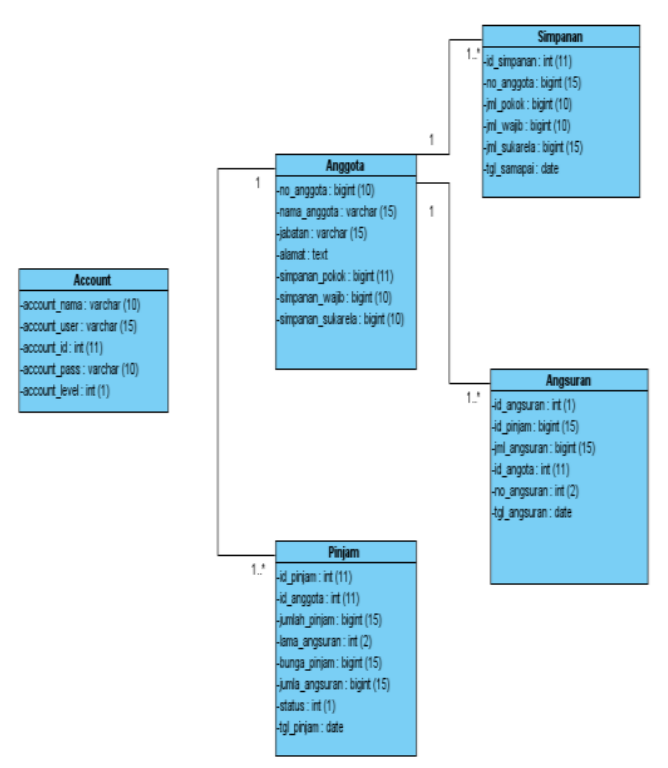




\section{Gambar 2 Class Diagram Simpan Pinjam}

\section{Koperasi}

Berdasarkan gambar 2 Class Diagram yang diusulkan terdapat :

a. 5 Class, himpunan dari objek-objek yang berbagi atribut serta operasi yang sama diantaranya guru, jabatan, absen, login, jam.

b. 3 Multiplicity, hubungan antara objek satu dengan objek lainnya yang mempunyai nilai.

\section{Literature Review}

Literature review adalah deskripsi hasil tinjauan pustaka yang dilakukan oleh peneliti (peserta KKP, TA/Skripsi) terhadap hasil penelitian yang telah ada dan dilakukan oleh peneliti lain mengenai objek atau tema yang sejenis dengan topik yang hendak diteliti/dibahas pada sebuah penelitian. Literature review merupakan landasan awal dan pendukung bagi peneliti yang akan dilakukan oleh peneliti sehingga menghindari pengulangan membuat hal yang sama dan melakukan pengembangan ketingkat yang lebih tinggi dalam rangka penyempurnaan/ melengkapi hal penelitian yang sudah ada sebelumnya.Pada penulisan kkp iniada penelitian sebelumnya yang dilakukan oleh beberapa mahasiswa/mahasiswi diantaranya sebagai berikut :
1. Penelitian yang dilakukan oleh Puji Hartatik (2010) penelitian yang dilakukan oleh Puji Hartatik berjudul " Perancangan Sistem Informasi Simpan Pinjam pada PT. Pratama Abadi Industry Tangerang". Metode yang diusulkan oleh penelitian ini menggunakan perancangan database yang baik dan juga dibuat aplikasi yang online sehingga sistem simpan pinjam lebih efektif dan efisien untuk mengurangi kesalahan dalam menginput data pada bagian payroll, maka diperlukan ketelitian.

2. Penelitian yang dilakukan oleh Cholisah Novianti penelitian yang dilakukan oleh Cholisah Novianti yang berjudul tentang “ Perancangan Sistem Informasi Pengajuan Permohonan Pinjaman Kredit Pada Koperasi Kodanau Tangerang”. Sistem yang diusulkan pada penelitian inimenggunakan aplikasih Program Visual Basic diharapkan dapat menangani permasalahan yang ada sehingga sistem pengajuan pinjaman kredit dapat berjalan dengan baik. Sistem ini dapat diakses dengan mudah melalui web browser oleh komputer client. Pada penelitian ini memiliki kesamaan dengan penelitian yang akan dijalankan tapi dalam penelitian ini sistem pengajuan pinjaman kredit hanya mengacu pada aturan sistem pengajuan pinjaman koperasi Kodanau, sehingga sistem ini tidak dapat digunakan oleh koperasi lain.

3. Penelitian yang dilakukan oleh Maesaroh Penelitian yang dilakukan oleh Maesaroh berjudul "Perancangan Sistem Pemodelan 
Dana Koperasi Pada PT. Indonesia Syntetic

Textile Milis ( Istem)". Sistem yang diusulkan dalam penelitian ini menggunakan program Visual Basic 6.0 penelitian ini membahas sistem pemodelan dana koperasi PT. Istem namun sistem yang dihasilkan masih bersifat bacth informatian yang artinya seluruh informasih di kumpulkan.

Hasil studi pustaka (literature review) ini mendemonstrasikan landasan yang kokoh serta alasan yang kuat untuk mengembangkan sistem simpan pinjam menjadi lebih baik.

\section{PEMECAHAN MASALAH}

Seperti yang dilihat dari permasalahan diatas maka diperlukan sebuah sistem untuk memaksimalkan proses koperasi simpan pinjam pegawai yang berlangsung di SMK YUPPENTEK 1. Dengan perancangan sebuah sistem koperasi simpan pinjam pegawai yang akan dibangun maka diharapkan agar sistem koperasi simpan pinjam pegawai yang sedang berjalan menjadi lebih efisien dan efektif.

Maka dari itu diciptakanlah website koperasi simpan pinjam pegawai dimana dengan sistem ini kegiatan ataupun proses simpan pinjam menjadi lebih cepat serta akurat, didalam sistem ini menggunakan metode Black Box Testing yaitu dengan melakukan test case ini bertujuan untuk menunjukkan fungsi PL tentang cara beroperasinya, apakah pemasukan data keluaran telah berjalan sebagaimana yang diharapkan dan apakah informasi yang disimpan secara eksternal selalu dijaga kemutakhirannya

\section{IMPLEMENTASI}

Rancangan Implementasi dapat digambarkan sebagai berikut :

1. Mengumpulkan data

Proses pengumpulan data digunakan sebagai perancangan sistem, sehingga data apa saja yang diperlukan dapat dianalisa dan dibuatkan sistem programnya.

2. Analisa Sistem

Menganalisa Penerimaan Nasabah yang sedang berjalan dan menganalisa suatu Penerimaan Nasabah untuk dicarikan kebenaranya yang selanjutnya akan diterapkan dalam suatu sistem yang dibutuhkan.

3. Perancangan Sistem

Merancang sistem dengan dasaran materi yang telah didapatkan dari analisa sistem yang telah dilakukan. Perancangan sistem ini dilakukan guna memenuhi kebutuhan untuk prmbuatan program.

\section{Pembuatan Program}

Dalam hal ini pembuatan program dilakukan secara bertahap dengan perlahan tapi pasti. Memasukan coding yang akan dieksekusi oleh komputer sesuai dengan yang dibutuhkan oleh User. 
5. Tes Program

Pengetesan program dilakukan untuk mengetahui kesalahan-kesalahan yang ada, dan untuk memastikan kebenaran dalam penulisan kode program kedalam komputer. Perbaikan Program Menambahkan atau mengurangi point-point tertentu yang tidak diperlukan sehingga program benar-benar dapat dioptimalkan sesuai dengan kebutuhan user.
6. Dokumentasi

Berbentuk catatan-catatan penting yang dilakukan selama melakukan sistem laporan hingga selesai. Dan ketika sistem berjalan masih tetap diperlukan dokumentasi yang suatu saat akan diperlukan

\begin{tabular}{|c|c|c|c|c|c|c|c|c|c|c|c|c|c|c|c|}
\hline \multirow{2}{*}{ No } & \multirow{2}{*}{ Jenis Kegiatan } & \multicolumn{4}{|c|}{ Maret-13 } & \multicolumn{4}{|c|}{ April-13 } & \multicolumn{4}{|c|}{ Mei-13 } & \multirow{2}{*}{$\begin{array}{c}\text { Juni } \\
13 \\
1\end{array}$} & \multirow{2}{*}{$\begin{array}{c}\text { Juli } \\
13 \\
1\end{array}$} \\
\hline & & 1 & 2 & 3 & 4 & 1 & 2 & 3 & 4 & 1 & 2 & 3 & 4 & & \\
\hline 1. & $\begin{array}{c}\text { Pengumpulan } \\
\text { Data }\end{array}$ & & & & & & & & & & & & & & \\
\hline 2. & $\begin{array}{c}\text { Perancangan } \\
\text { Sistem }\end{array}$ & & & & & & & & & & & & & & \\
\hline 3. & $\begin{array}{l}\text { Pembuatan } \\
\text { Program }\end{array}$ & & & & & & & & & & & & & & \\
\hline 4. & Test Program & & & & & & & & & & & & & & \\
\hline 5. & $\begin{array}{l}\text { Evaluasi } \\
\text { Program }\end{array}$ & & & & & & & & & & & & & & \\
\hline 6. & $\begin{array}{c}\text { Perbaikan } \\
\text { Program }\end{array}$ & & & & & & & & & & & & & & \\
\hline 7. & Training User & & & & & & & & & & & & & & \\
\hline 8. & $\begin{array}{c}\text { Implementasi } \\
\text { Program }\end{array}$ & & & & & & & & & & & & & & \\
\hline 9. & Dokumentasi & & & & & & & & & & & & & & \\
\hline
\end{tabular}

Gambar 2 Class Diagram Simpan Pinjam Koperasi 


\section{KESIMPULAN}

Dari uraian yang telah dijelaskan pada pembahasan dapat disimpulkan sebagai berikut

1. Berdasarkan uraian dan pembahasan pada bab-bab sebelumnya serta hasil analisa yang dilakukan oleh penulis mengenai sistem informasi sistem pinjam koperasi pada SMK Yuppentek 1 Tangerang belum sepenuhnya maksimal terutama dalam proses pinjaman uang, pembuatan laporannya masih manual melakukan pencatatan dahulu, kemudian dimasukan ke Microsoft Excel, sehingga dalam proses pinjaman koperasi sering terjadi penumpukan surat permohonan pinjaman dari pihak anggaran, sering terjadi kesalahan dalam pemotongan kasbon sehingga dilakukan pemrosesan ulang.

2. Masalah yang ditemukan oleh penulis selama observasi dilakukan ini adalah tidak ada

backup data secara otomatis dan kurang memadainya tempat untuk menyimpan data-data, sehingga terjadi penumpukan kertas-kertas.

3. Dari permasalahan yang ada, penulis mengusulkan Perancangan Sistem Informasi Simpan Pinjam Koperasi Pada SMK Yuppentek 1 Tangerang berbasis web dengan menggunakan database MySql yang terdiri dari data anggota, simpanan pinjaman dan angsuran yang terdapat menu login admin dan anggota koperasi dapat melakukan pengecekan saldo.

\section{DAFTAR PUSTAKA}

[1] Kadir, Abdul. 2011. Dasar Pemrograman JavaTM 2. Yogyakarta : Andi.

[2] Nugroho, Adi. 2010. L. Jeffery et al, 2004 Unified Modeling Language (UML).

[3] Ary Budi Warsito. 2010. Literature adalah kesasteraan atau kepustakaan.

[4] Berorientasi Objek. Bandung : Informatika.

[5] CCIT 2010. Warsito,et all. Digital Liblary Modelling Supporting For Knowledge Management. Jurnal CCIT Vol.3 No.3 September 2010.

[6] Gordon B. 2010. The Economic Theory of a Common Property Resource : The Fishery. Journal of Political Economy.

[7] Guritno. Sudaryono dan Untung Raharja dalam Jurnal CCIT 2010.

[8] Hidayat. 2010. Modul Ajar Instalasi Listrik Kapal. PPNS-ITS.

[9] Haerani : Isna 2009. Perancangan Sistem Informasi Simpan Pinjam Pada Koperasi Kab.Tangerang : BIna Sejahtera.

[10] Jogiyanto H.M. 2010. Teori Portofolio dan Analisis Investasi.

[11] Jurnal CCIT. 2012. Maimunah. dkk Media Company Profile sebagai Sarana Penunjang Informasi dan Promosi. Jurnal CCIT Vol.5 2012 No.3. Tangerang Perguruan Tinggi Raharja.

[12] Liyudi. 2010. Pengolahan Data. 
[13] Padeli dalam Jurnal CCIT 2010. Membangun (E-Procurement) Pengadaan Barang Dan Jasa.

[14] Hartatik, Puji. 2010. berjudul Perancangan Sistem Informasi Simpan Pinjam Koperasi Sejahtera Pada PT. Pratama Tangerang : Abadi Industri.

[15] Sistem Informasi dan Intelegensi Buatan. Yogyakarta : Andi.
[16] Maesaroh, Titin. 2011. Berjudul Perancangan Sistem Pemodelan Dana Koperasi. Pada PT. Indonesia Synthetic Textile Milis PT. Istem.

[17] Dengan Prinsip Good Coorporate Dengan Visual UML 2(1).70. Tangerang : Jurnal CCIT.

[18] Widodo. 2011. bahan belajar mandiri. Bandung : UPI. 